\title{
Evaluation of the Accuracy of Digital Models Obtained Using Intraoral and Extraoral Scanners versus Gold Standard Plaster Model (Diagnostic Accuracy Study)
}

\author{
Mohammed Amr Labib*, Amr Ragab El-Beialy, Khaled Hazem Attia \\ Department of Orthodontics and Dentofacial Orthopedics, Faculty of Dentistry, Cairo University, Giza, Egypt \\ Email: *amr.elbeialy@dentistry.cu.edu.eg
}

How to cite this paper: Labib, M.A., El-Beialy, A.R. and Attia, K.H. (2020) Evaluation of the Accuracy of Digital Models Obtained Using Intraoral and Extraoral Scanners versus Gold Standard Plaster Model (Diagnostic Accuracy Study). Open Journal of Medical Imaging, 10, 151-163. https://doi.org/10.4236/ojmi.2020.103015

Received: August 7, 2020

Accepted: September 26, 2020

Published: September 29, 2020

Copyright $\odot 2020$ by author(s) and Scientific Research Publishing Inc. This work is licensed under the Creative Commons Attribution International License (CC BY 4.0).

http://creativecommons.org/licenses/by/4.0/

(c) (i) Open Access

\begin{abstract}
Introduction: Digital models showed promising results for orthodontic diagnosis and treatment planning. Digital models can be obtained from alginate impressions as well as direct intra-oral scanners. Studies assessing the accuracy of digital models have shown digital models to be valid, clinically acceptable, and more quickly obtainable. With the advent of new scanners with better scanning technology researches are necessary to evaluate their accuracy and reliability. Aim of Study: To evaluate the diagnostic accuracy of 3D digital models obtained through intraoral and extraoral scanning modalities to the reference gold standard plaster model. Material \& Methods: Twenty-four adult male and female subjects were randomly selected for this study. The intraoral scanners evaluated in this study were Sirona (CEREC Omnicam) and 3 shape (TRIOS 3 ), while the laboratory scanners used were Sirona (inEos X5), and 3 shape (D850). Intra-oral scanning of the subjects and extra-oral scanning of their alginate impressions, plaster models of the alginate impression, rubber base impression, and plaster model of their rubber base impression were done. Linear dental measurements included intermolar width, interpremolar width, intercanine width, mesiodistal width of the $1^{\text {st }}$ permanent molar, $1^{\text {st }}$ premolar, canine and central incisor and arch width. All data were collected, tabulated and subjected to statistical analysis. Results: Small differences between the plaster and digital models were observed. Intra-observer reliability analysis for 14 out of the 16 measurements showed that all variables exhibited good to excellent reliability. Conclusions: There was no difference between the digitization using the intraoral scanner or the laboratory scanner. The most accurate digitization technique was the 3 Shape laboratory scanner of the cast of the alginate impression. The inEos X5
\end{abstract}


showed the highest error of digitization of the alginate and rubber base impressions.

\section{Keywords}

Study Models, Digital Models, Orthodontics, Intra-Oral Scanners, Impression Scanner

\section{Introduction}

The orthodontic discipline has been embracing new technologies over the past years. The paperless setup has been one of those technologies introduced to the orthodontic practice. The biggest obstacle facing the paperless orthodontic office is the plaster study model. The plaster models are indispensable, because they are considered the cornerstone gold standard in orthodontic diagnosis and treatment planning and cases documentation. Besides, they are essential for educational purposes, evaluating treatment progress, and research reasons, not to mention their medico-legal significance. In this respect, there is a need to retain dental models for long periods, with associated problems of storage, risk of damage or even loss [1]. The transformation of orthodontic plaster models into digital models is gaining popularity due to the superiority of digital models to plaster models in storage, retrieval, and sharing of information. Digital models can be used successfully for orthodontic diagnosis and treatment planning. Besides, working in a virtual environment shortens the time required for each procedure [2] [3].

Studies assessing the accuracy of measurements obtained from digital models such as tooth size, arch width, arch length, space analysis, overjet, overbite, midline discrepancy, Bolton tooth size analysis, and molar and canine relationships have shown these models to be valid, clinically acceptable, and more quickly obtainable [4] [5] [6]. Digital models are generated from alginate impressions as well as from intra-oral scanners to prove their reliability and accuracy [1] [5] [7] [8]. Various factors affect the accuracy and reproducibility such as tooth position, anatomical variations as well as inter-examiner variability due to lack of familiarity with the utilized software [9].

Abduo and Elseyoufi (2018) [10] conducted a systematic review to evaluate the accuracy of the available intra-oral scanning systems for dental impression, and identify the influencing factors on accuracy when comparing digital models to plaster models. They concluded that the intra-oral scanning systems could be reliably used for diagnostic purposes and short-span scanning when compared to conventional impressions. They reported that the intra-oral scanning system is susceptible for more deviation when it comes to whole arch scanning.

Felter, et al. (2018) [11] recommended that software programs for visualization and analysis of digital orthodontic models, apart from presenting the necessary features for diagnosis and treatment planning, need to be user-friendly. 
With the advent of new scanners with better scanning technology researches are necessary to evaluate their claimed accuracy and reliability.

The aim of the present work was to compare the diagnostic accuracy of dental measurements on digital models in relation to the gold standard of plaster models via 10 digitization techniques. The null hypothesis states that there is no difference in diagnostic accuracy between any of the tested modalities.

\section{Material \& Methods}

Twenty-four adult male and female subjects were enrolled in this study from the outpatient clinic of the Department of Orthodontics and Dentofacial Orthopedics, Faculty of Dentistry. Randomization of the sample irrespective to the degree of crowding of the arches was done. The study included adult patients seeking orthodontic treatment, presence of permanent dentition only with exclusion of cleft lip and palate patients.

The digitization included 2 techniques: intraoral scanning of the patients' dentition via Sirona (CEREC Omnicam) (Figure 1) and 3 shape (TRIOS 3) (Figure 2), and extra-oral scanning of the plaster models using two lab scanners Sirona (inEos X5) (Figure 3), and 3 shape (D850) (Figure 4). The laboratory scanning was done for the alginate impression (Zermack Hydrogum 5 alginate material) (Figure 5), the plaster model of the same alginate impression, the rubber base impression (Zermack Elite HD+) (Figure 6) and the plaster model obtained from the same rubber base impression. The physical plaster model of the rubber base condensation silicone impression (Polysiloxane addition silicon) was considered the gold reference standard.

The intra-oral scanning of the subjects was done by inserting the scanner camera in the mouth and scanning each quadrant of the jaw, then scanning the bite for occlusion. A 3D picture was then produced on the monitor. For automatic manipulation of fully surfaced 3D digital models to produce STL images,

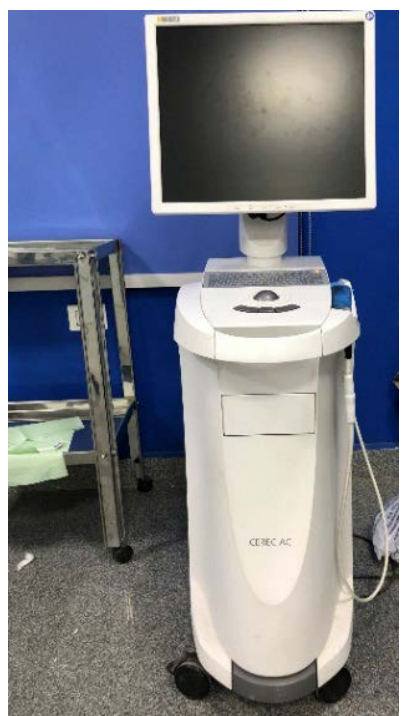

Figure 1. Photograph showing Sirona (CEREC Omnicam) intra-oral scanner. 


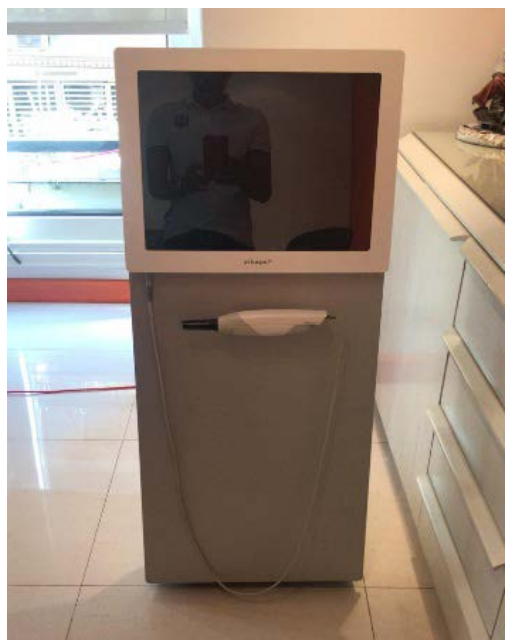

Figure 2. Photograph showing 3-shape (TRIOS 3) intra-oral scanner.

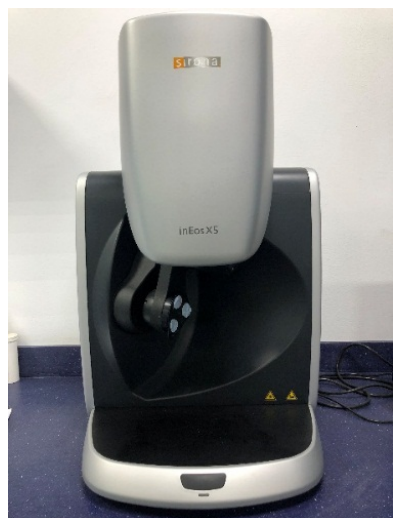

Figure 3. Photograph showing Sirona (inEosX5).

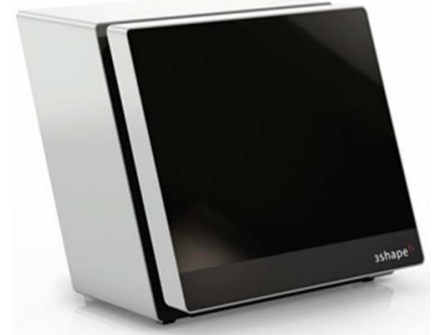

Figure 4. Photograph showing 3 shape (D850) scanner.

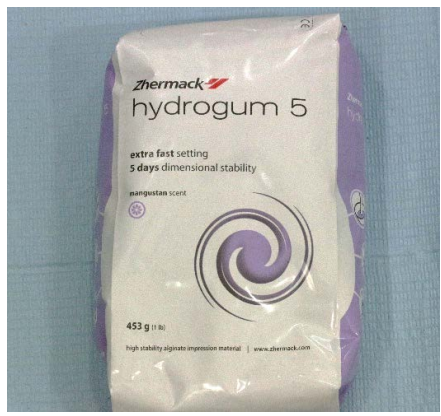

Figure 5. Photograph showing Zermack Hydrogum 5 alginate material. 
the CEREC SW 4.6.1 scanning software and dental system software was used for the Sirona scanner, while the TRIOS scanning software was used for the 3 Shape scanner.

The impressions and their poured replicas were scanned after being transferred in sealed labelled plastic containers. The impressions and casts were inserted in the scanner to start the scanning process. After scanning was in $3 \mathrm{D}$ (Figure 7), 3 Shape Dental System premium scanning software and Sirona INLAB-15 scanning software were used for automatic manipulation of fully surfaced 3D digital models to produce STL images (Figure 8).

All STL images were collected for impressions and casts to be analyzed using 3 shape Ortho analyzer software for the following linear dental measurements: intermolar width, interpremolar width, intercanine width, mesiodistal width of

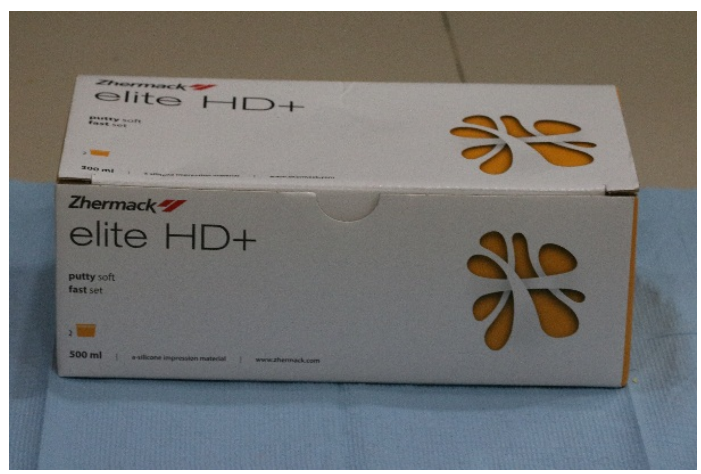

Figure 6. Photograph showing addition silicon impression material (Zermack Elite $\mathrm{HD}+)$.

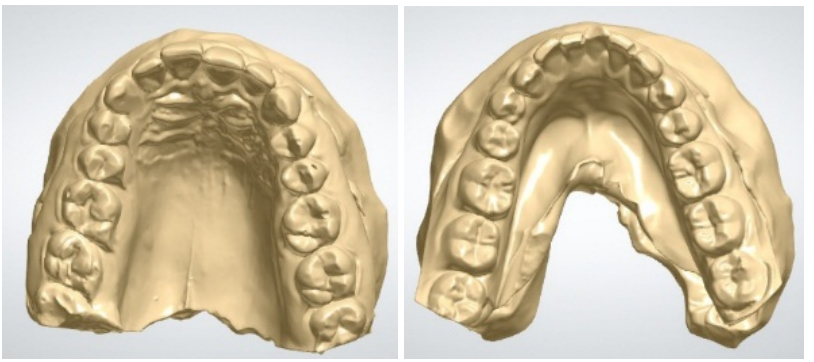

Figure 7. Photograph showing fully surfaced 3D digital models produced as STL images.

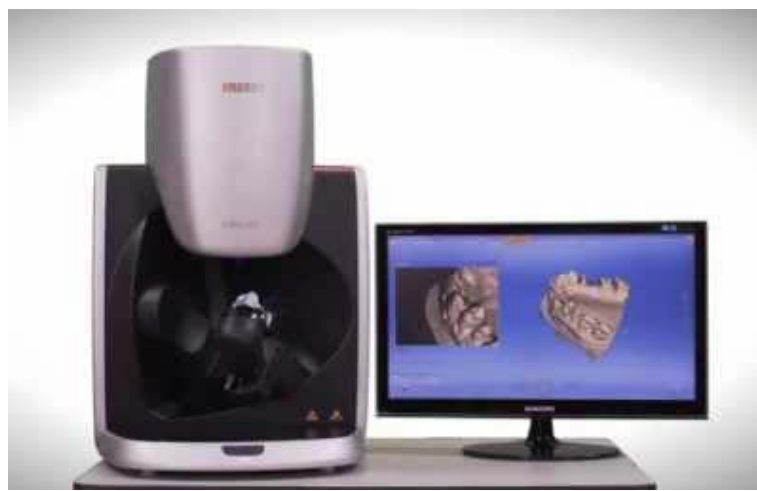

Figure 8. Photograph showing images captured and produced in 3D. 


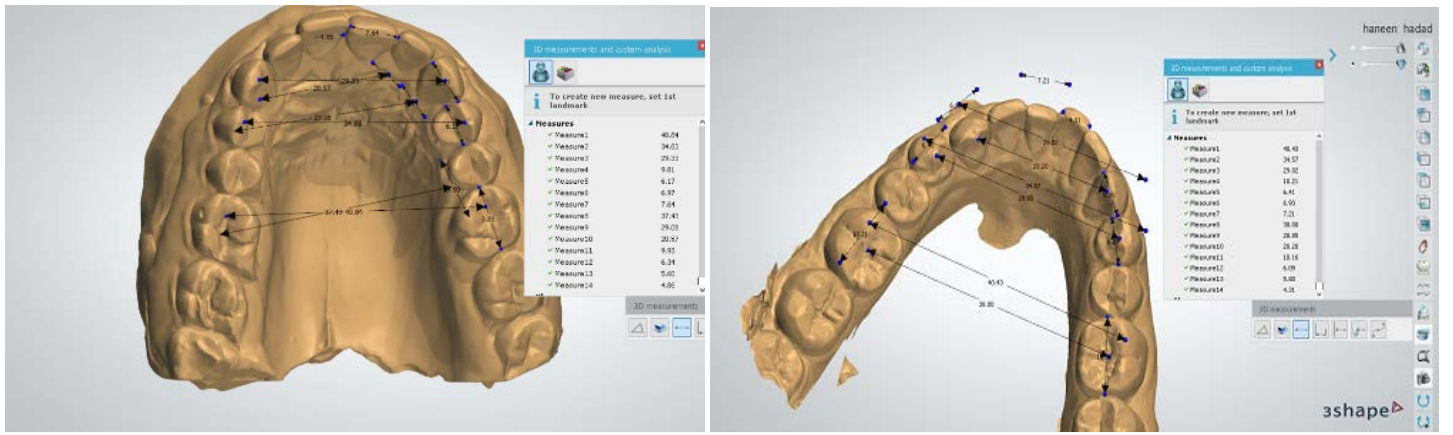

(a)

(b)

Figure 9. Photograph showing linear dental measurements taken for upper (a) and lower (b) casts.

first permanent molar, first premolar, canine, and central incisor, and arch depth (Figure 9). All images were assessed on the computer workstation by two orthodontists independently, and subsequently a consensus reading was performed. The orthodontists (O1 and $\mathrm{O} 2)$ were blinded to the modality for digitization of each model. The same assessors performed the same measurements on the physical reference standard models using digital caliber after being anonymous. A positivity cutoff was done if clinical measurements exceeded $0.5 \mathrm{~mm}$.

All data were collected, tabulated and subjected to statistical analysis. Statistical analysis was performed by SPSS in general (version 16), in addition to Microsoft Office Excel was used for data handling and graphical presentation. Analysis of variance one-way ANOVA was used for comparing the mean Dahlberg Error (DE) between all methods. For comparing the mean Dahlberg error of any two methods t-test was applied. Significance level was set at $p<0.05$, while $p<0.01$ was considered highly significant. Two-tailed test assumption was applied all through the study.

\section{Results}

The results of this study aimed at comparing the diagnostic accuracy of digital models obtained via 10 digitization techniques to the reference standard of direct dental measurements of the physical plaster as seen in Tables 1-4.

Comparing the mean Dahlberg for all methods used, scanning the alginate cast using 3 shape extra-oral scanner (D850) showed the least mean Dahlberg error. On the other hand, scanning alginate impression using extra-oral scanner of Sirona (inEosX5) displayed the highest error.

\section{Discussion}

Digital models are becoming the standard orthodontic record in many dental practices around the world. They have been accepted to substitute for the disadvantages of plaster models which until recent years were considered as the gold standard in diagnosis and treatment planning. Disadvantages of plaster models such as the risk of fracture, storage costs, time needed for their retrieval, the considerable risk of damage, and their use for consultation or review entails 
Table 1. Difference of mean linear measurements with gold standard in $\mathrm{mm}$.

\begin{tabular}{|c|c|c|c|c|c|c|c|c|c|c|}
\hline \multirow[b]{2}{*}{$\begin{array}{l}\text { Linear Dental } \\
\text { Measurement }\end{array}$} & \multicolumn{5}{|c|}{ 3SHAPE } & \multicolumn{5}{|c|}{ SIRONA } \\
\hline & $\begin{array}{l}3 \text { shape } \\
\text { extraoral } \\
\text { alginate } \\
\text { cast }\end{array}$ & $\begin{array}{c}3 \text { shape } \\
\text { extraoral } \\
\text { alginate } \\
\text { impression }\end{array}$ & $\begin{array}{l}3 \text { shape } \\
\text { extraoral } \\
\text { rubber cast }\end{array}$ & $\begin{array}{l}3 \text { shape } \\
\text { extraoral } \\
\text { rubber } \\
\text { impression }\end{array}$ & $\begin{array}{l}3 \text { shape } \\
\text { intraoral }\end{array}$ & $\begin{array}{l}\text { sirona } \\
\text { intraoral }\end{array}$ & $\begin{array}{c}\text { eos } \\
\text { alginate } \\
\text { cast }\end{array}$ & $\begin{array}{c}\text { eos } \\
\text { alginate } \\
\text { impression }\end{array}$ & $\begin{array}{l}\text { eos rubber } \\
\text { cast }\end{array}$ & $\begin{array}{l}\text { eos rubber } \\
\text { impression }\end{array}$ \\
\hline $\operatorname{arch} \operatorname{dept} \mathrm{L}$ & -0.14 & 0.10 & -0.10 & 0.25 & -0.02 & 0.25 & 0.06 & 0.38 & -0.16 & -0.17 \\
\hline $\operatorname{arch} \operatorname{dept} U$ & 0.21 & 0.69 & 0.48 & 0.44 & 0.55 & 0.54 & 0.29 & 0.41 & 0.20 & 0.63 \\
\hline Intercanine width $\mathrm{L}$ & 0.05 & 0.38 & 0.37 & 0.58 & 0.53 & 0.55 & 0.37 & 0.71 & 0.31 & -0.05 \\
\hline Intercanine width $\mathrm{U}$ & -0.16 & 0.52 & 0.38 & 0.71 & 0.58 & 0.46 & 0.39 & 0.99 & 1.30 & 0.67 \\
\hline Intermolar width $\mathrm{L}$ & 0.22 & 0.34 & 0.35 & 0.44 & 0.64 & 0.31 & 0.43 & 0.42 & 0.37 & -0.11 \\
\hline Intermolar width $\mathrm{U}$ & -0.06 & 0.33 & 0.50 & 0.51 & 0.58 & 0.64 & 0.55 & 1.36 & 0.40 & 0.94 \\
\hline Interpremolar width L & -0.19 & 0.20 & 0.06 & 0.36 & 0.23 & 0.09 & 0.14 & 0.58 & 0.21 & -0.29 \\
\hline Interpremolar width $\mathrm{U}$ & -0.26 & 0.47 & 1.10 & 0.75 & 0.54 & 0.35 & 0.21 & 1.25 & 0.21 & 0.99 \\
\hline MD canine $\mathrm{L}$ & -.001 & 0.16 & 0.23 & 0.04 & 0.13 & 0.24 & 0.13 & 0.14 & -0.03 & 0.42 \\
\hline MD canine $U$ & 0.20 & 0.13 & 0.21 & 0.10 & 0.15 & 0.31 & 0.09 & 0.28 & 0.16 & 0.17 \\
\hline MD central incisor L & -0.04 & 0.13 & 0.19 & 0.11 & 0.19 & 0.17 & 0.10 & 0.14 & 0.08 & 0.30 \\
\hline MD central incisor $\mathrm{U}$ & 0.16 & 0.31 & 0.29 & 0.39 & 0.38 & 0.48 & 0.36 & 0.35 & 0.36 & 0.36 \\
\hline $\begin{array}{l}\text { MD first permanent } \\
\text { molar L }\end{array}$ & -0.04 & -0.02 & 0.02 & 0.01 & -0.11 & 0.01 & -0.05 & 0.12 & 0.03 & 0.00 \\
\hline $\begin{array}{l}\text { MD first permanent } \\
\text { molar } \mathrm{U}\end{array}$ & 0.00 & 0.05 & -0.10 & -0.07 & 0.02 & 0.06 & 0.04 & 0.08 & -0.07 & 0.01 \\
\hline MD first premolar L & 0.02 & 0.02 & 0.12 & 0.29 & 0.05 & 0.21 & 0.25 & 0.34 & 0.25 & 0.34 \\
\hline MD first premolar $U$ & -0.07 & -0.17 & 0.08 & 0.14 & -0.07 & 0.03 & 0.02 & -0.12 & -0.01 & -0.03 \\
\hline
\end{tabular}

Table 2. Descriptive statistics of the mean Dahlberg error of all methods.

\begin{tabular}{|c|c|c|c|c|c|c|c|c|}
\hline & $\mathrm{N}$ & Mean & SD & SEM & $\begin{array}{l}\text { Lower } \\
\text { Bound }^{*}\end{array}$ & $\begin{array}{c}\text { Upper } \\
\text { Bound }^{*}\end{array}$ & Minimum & Maximum \\
\hline 3 shape extra oral alginate cast & 16 & 0.29 & 0.07 & 0.02 & 0.25 & 0.32 & 0.21 & 0.40 \\
\hline 3 shape extraoral alginate impression & 16 & 0.63 & 0.38 & 0.09 & 0.43 & 0.83 & 0.22 & 1.14 \\
\hline 3 shape extraoral rubber cast & 16 & 0.66 & 0.56 & 0.14 & 0.37 & 0.96 & 0.17 & 2.28 \\
\hline 3 shape extraoral rubber impression & 16 & 0.64 & 0.40 & 0.10 & 0.43 & 0.86 & 0.12 & 1.22 \\
\hline 3 shape intraoral & 16 & 0.62 & 0.38 & 0.10 & 0.41 & 0.82 & 0.21 & 1.30 \\
\hline sirona intraoral & 16 & 0.58 & 0.35 & 0.09 & 0.40 & 0.77 & 0.21 & 1.08 \\
\hline eos alginate cast & 16 & 0.57 & 0.36 & 0.09 & 0.38 & 0.76 & 0.19 & 1.13 \\
\hline eos rubber cast & 16 & 0.64 & 0.53 & 0.13 & 0.36 & 0.92 & 0.15 & 2.21 \\
\hline eos rubber impression & 16 & 0.55 & 0.45 & 0.11 & 0.31 & 0.79 & 0.2 & 1.41 \\
\hline
\end{tabular}

${ }^{*} 95 \%$ Confidence Interval for Mean. 
Table 3. Sorted mean Dahlberg error of all methods.

\begin{tabular}{ccc}
\hline Method & Mean & SD \\
\hline 3 shape extra oral alginate cast & 0.29 & 0.07 \\
eos rubber impression & 0.55 & 0.45 \\
eos alginate cast & 0.57 & 0.36 \\
sirona intraoral & 0.58 & 0.34 \\
3 shape intraoral & 0.62 & 0.38 \\
3 shape extraoral alginate impression & 0.63 & 0.38 \\
eos rubber cast & 0.64 & 0.53 \\
3 shape extraoral rubber impression & 0.64 & 0.40 \\
3 shape extraoral rubber cast & 0.66 & 0.56 \\
eos alginate impression & 0.78 & 0.54 \\
\hline
\end{tabular}

Table 4. $\mathrm{t}$-test for comparison of the method with lowest mean Dahlberg error (3 shape extra oral alginate cast) with other methods.

\begin{tabular}{|c|c|c|c|c|c|c|c|c|}
\hline \multicolumn{2}{|c|}{ Comparators } & \multirow{2}{*}{$\begin{array}{c}\text { Mean } \\
0.29\end{array}$} & \multirow{2}{*}{$\begin{array}{c}\text { SD } \\
0.07\end{array}$} & \multirow{2}{*}{$\begin{array}{c}\text { Mean } \\
0.55\end{array}$} & \multirow{2}{*}{$\begin{array}{c}\text { SD } \\
0.45\end{array}$} & \multirow{2}{*}{$\begin{array}{c}\mathbf{t} \\
2.21\end{array}$} & \multicolumn{2}{|c|}{ P Value } \\
\hline 3 shape extra oral alginate cast & eos rubber impression & & & & & & 0.03516 & $\mathrm{P}<0.05 \mathrm{~S}$ \\
\hline 3 shape extra oral alginate cast & eos alginate cast & 0.29 & 0.07 & 0.57 & 0.36 & 2.89 & 0.00711 & $\mathrm{P}<0.01 \mathrm{HS}$ \\
\hline 3 shape extra oral alginate cast & sirona intraoral & 0.29 & 0.07 & 0.58 & 0.34 & 3.16 & 0.00358 & $\mathrm{P}<0.01 \mathrm{HS}$ \\
\hline 3 shape extra oral alginate cast & 3 shape intraoral & 0.29 & 0.07 & 0.62 & 0.38 & 3.18 & 0.00344 & $\mathrm{P}<0.01 \mathrm{HS}$ \\
\hline 3 shape extra oral alginate cast & 3 shape extraoral alginate impression & 0.29 & 0.07 & 0.63 & 0.38 & 3.32 & 0.00235 & $\mathrm{P}<0.01 \mathrm{HS}$ \\
\hline 3 shape extra oral alginate cast & eos rubber cast & 0.29 & 0.07 & 0.64 & 0.53 & 2.50 & 0.01813 & $\mathrm{P}<0.05 \mathrm{~S}$ \\
\hline 3 shape extra oral alginate cast & 3 shape extraoral rubber impression & 0.29 & 0.07 & 0.64 & 0.40 & 3.23 & 0.00300 & $\mathrm{P}<0.01 \mathrm{HS}$ \\
\hline 3 shape extra oral alginate cast & 3 shape extraoral rubber cast & 0.29 & 0.07 & 0.66 & 0.56 & 2.53 & 0.01680 & $\mathrm{P}<0.05 \mathrm{~S}$ \\
\hline 3 shape extra oral alginate cast & eos alginate impression & 0.29 & 0.07 & 0.78 & 0.54 & 3.30 & 0.00251 & $\mathrm{P}<0.01 \mathrm{HS}$ \\
\hline
\end{tabular}

manipulation and transportation needs have been overcome. Despite their advantages yet their disadvantages lie in their cost, computer failure, software failure or manufacturer insolvency could possibly mean that the models may become inaccessible for a time or forever [2] [3].

Most digital models are made from alginate impressions which are either scanned directly or poured in plaster and then scanned. The development of chair side oral scanners allows direct digital acquisition of the clinical situation in the oral cavity to eliminate the need for conventional impressions. The accuracy of dental model analysis is important for exploitation digital models as diagnostic tools [12] [13].

The diagnostic accuracy and reliability of the digital model system has been met by the results of the present study. The program for manipulation and measurement of the digital models is easy to learn and user friendly. In addition, image setups are easy to store as they do not require large physical spaces in comparison to plaster models. 
Significant differences between manual and digital measurements may be attributed to the intrinsic differences between the 2 methods as the latter shows a 3-dimensional view that allows better location of the reference points, and it contains digital tools to measure diameters and distances along selected planes. The models measured manually and digitally showed certain similarities for both vertical and transverse measurements, because in most of the measurements, no significant difference was observed. These results are consistent with several studies [14]-[24].

Intra-observer reliability analysis for 14 out of the 16 measurements showed that all variables exhibited good to excellent reliability, whereas the two measurements for mesio-distal canine width in the lower arch and mesiodistal central incisor in the lower arch were far from each other most probably by unintended mistake (6.14 and 4.58), such that if these values were excluded the reliability would be much better.

Digital scanning of 3 shape extra oral alginate casts yielded the highest ranking of methods according to relative Dahlberg error for all variables. This was seen in 7 out of the 16 measurements. The difference between the two methods did not exceed $1 \mathrm{~mm}$ for any of the parameters and both methods may be considered to be repeatable with acceptable differences between the two techniques. The results are consistent with previous studies who also found good reliability between the two methods [1] [16].

Intra-oral scanning has its own challenges, such as presence of saliva, soft tissue movement presented by the tongue, coupled with the presence of metallic reflective restorations making intra-oral surfaces difficult to capture. Inaccuracies with the digital technique could also be partly attributed to difficulty in locating the greatest mesio-distal width of the tooth for arch length assessment. Despite the rotation functions and magnification in the software, accurate point location remains difficult. Parameters such as inter-canine and inter-molar widths, where landmark identification was easier, showed good repeatability and reproducibility when considering both techniques. This was also found with several studies carried out [25] [26] [27] [28].

Several studies showed that all linear dental measurements of digital models obtained from scans of alginate impressions and plaster model were valid, reliable, and reproducible for diagnostic purposes [25] [28] [29] [30]. In the current study oral scan values tend to be greater than the matching impression scan values. These values when compared to overall bias can be considered negligible and clinically insignificant except for inter canine width in 3 shape extra-oral rubber impression, eos alginate impression, eos rubber cast; inter premolar width in eos alginate impression and eos rubber impression; inter molar width in 3 shape extra-oral rubber impression, eos alginate impression, eos rubber impression. This could be attributed to the inaccuracy of scanning impressions. As regards the intercanine width which is a small measurement such that any minute error represents a high percentage of the original measurement. 
The small differences between the plaster and digital models were statistically significant. The digital models were reasonably reliable and accurate. They could provide the clinician with adequate information to develop a treatment plan and thus eliminate the need for storing plaster casts. As regards the clinical significance, the true test would be to determine whether treatment plans produced with computer-based models differed significantly from treatment plans produced with plaster models. In turn, the results of the treatment from the two different sets of models would determine the true value of digital models.

Finally, based on the results of this study, it is reasonable to conclude that 3-dimensional digital models acquired by intra oral scanning of the dentition are as accurate and reliable as extra-oral scanned models to be used confidently in the process of diagnosis and treatment planning.

\section{Limitation of the Study}

In certain instances, incomplete 3D scans were generated, due to error during scanning. Since the essence of the current study is to assess the outcome of the two scanners for the different impressions and casts, some measurements were excluded from the incomplete scans due to the difficulty in attaining the measurement.

\section{Conclusion \& Recommendation}

It could be concluded that the digitization of dentition produced an accurate replica of the dentition compared to the gold standard. There was no difference between the digitization using the intraoral scanner or the laboratory scanner. The most accurate digitization technique was the 3 Shape laboratory scanner of the cast of the alginate impression. The inEos X5 showed the highest error of digitization of the alginate and rubber base impressions. Therefore, 3-dimensional digital models acquired by intra oral scanning of the dentition are as accurate and reliable as extra-oral scanned models to be used confidently in the process of diagnosis and treatment planning.

\section{Conflicts of Interest}

The authors declare no conflicts of interest regarding the publication of this paper.

\section{References}

[1] Dalstra, M and Melsen, B (2009) From Alginate Impressions to Digital Virtual Models: Accuracy and Reproducibility. Journal of Orthodontics, 36, 36-41. https://doi.org/10.1179/14653120722905

[2] Patzelt, G., Bishti, S., Stampf, S. and Att, W. (2014) Accuracy of Computer-Aided Design/Computer-Aided Manufacturing Generated Dental Casts Based on Intraoral Scanner Data. Journal of the American Dental Association, 145, 1133-1140. https://doi.org/10.14219/jada.2014.87

[3] Patzelt, S.B.M., Lamprinos, C., Stampf, S. and Att, W. (2014) The Time Efficiency of 
Intraoral Scanners: An In-Vitro Comparative Study. Journal of the American Dental Association, 145, 542-551. https://doi.org/10.14219/jada.2014.23

[4] Bootvong, K., Liu, Z., McGrath, C., Hägg, U., Wong, R.W.K., Bendeus, M. and Yeung, S. (2010) Virtual Model Analysis as an Alternative Approach to Plaster Model Analysis: Reliability and Validity. European Journal of Orthodontics, 32, 589-595. https://doi.org/10.1093/ejo/cjp159

[5] Fleming, P.S., Marinho, V. and Johal, A. (2011) Orthodontic Measurements on Digital Study Models Compared with Plaster Models: A Systematic Review. Orthodontics \& Craniofacial Research, 14, 1-16. https://doi.org/10.1111/j.1601-6343.2010.01503.x

[6] Sousa, M.V., Vasconcelos, E.C., Janson, G., Garib, D. and Pinzan, A. (2012) Accuracy and Reproducibility of 3-Dimensional Digital Model Measurements. American Journal of Orthodontics and Dentofacial Orthopedics, 142, 269-273.

https://doi.org/10.1016/j.ajodo.2011.12.028

[7] Cuperus, A.M., Harms, M.C., Rangel, F.A., Bronkhorst, E.M., Schols, J.G. and Breuning, K.H. (2012) Dental Models Made with an Intraoral Scanner: A Validation Study. American Journal of Orthodontics and Dentofacial Orthopedics, 142, 308-313. https://doi.org/10.1016/j.ajodo.2012.03.031

[8] Rossini, G., Parrini, S., Castroflorio, T., Deregibus, A. and Debernardi, C.L. (2016) Diagnostic Accuracy and Measurement Sensitivity of Digital Models for Orthodontic Purposes: A Systematic Review. American Journal of Orthodontics and Dentofacial Orthopedics, 149, 161-170. https://doi.org/10.1016/j.ajodo.2015.06.029

[9] Leifert, M.F., Leifert, M.M., Efstratiadis, S.S. and Cangialosi, T.J. (2009) Comparison of Space Analysis Evaluations with Digital Models and Plaster Dental Casts. American Journal of Orthodontics and Dentofacial Orthopedics, 136, 16.E1-16.E4. https://doi.org/10.1016/j.ajodo.2008.11.019

[10] Abduo, J. and Elseyoufi, M. (2018) Accuracy of Intraoral Scanners: A Systematic Review of Influencing Factors. European Journal of Prosthodontics and Restorative Dentistry, 26, 101-121.

[11] Felter, M., Lenza, M.M., Lenza, M.G., Shibazaki, W.M. and Silva, R.F. (2018) Comparative Study of The Usability of Two Software Programs for Visualization And Analysis of Digital Orthodontic Models. Journal of Dental Research, Dental Clinics, Dental Prospects, 12, 213-220. https://doi.org/10.15171/joddd.2018.033

[12] Grünheid, T., McCarthy, S.D. and Larson, B.E. (2014) Clinical Use of a Direct Chairside Oral Scanner: An Assessment of Accuracy, Time, and Patient Acceptance. American Journal of Orthodontics and Dentofacial Orthopedics, 146, 673-682. https://doi.org/10.1016/j.ajodo.2014.07.023

[13] Reuschl, R.P., Heuer, W., Stiesch, M., Wenzel, D. and Dittmer, M.P. (2016) Reliability and Validity of Measurements on Digital Study Models and Plaster Models. European Journal of Orthodontics, 38, 22-26. https://doi.org/10.1093/ejo/cjv001

[14] Atia, M., El-Gheriani, A. and Ferguson, D. (2015) Validity of 3 Shape Scanner Techniques: A Comparison with the Actual Plaster Study Casts. Biometrics \& Biostatistics International Journal, 2, 64-69. https://doi.org/10.15406/bbij.2015.02.00026

[15] Barretoa, M., Faberb, J., Vogelc, C. and Araujod, T. (2016) Reliability of Digital Orthodontic Setups. The Angle Orthodontist, 86, 255-259. https://doi.org/10.2319/120914-890.1

[16] Jacob, H., Wyatt, G. and Buschang, P. (2015) Reliability and Validity of Intraoral and Extraoral Scanners. Progress in Orthodontics, 16, Article No. 38.

https://doi.org/10.1186/s40510-015-0108-7 
[17] Saleh, W., Ariffin, E., Sherriff, M. and Bister, D. (2015) Accuracy and Reproducibility of Linear Measurements of Resin, Plaster, Digital and Printed Study-Models. Journal of Orthodontics, 42, 301-306. https://doi.org/10.1179/1465313315Y.0000000016

[18] Czarnota, J., Hey, J. and Fuhrmann, R. (2016) Measurements Using Orthodontic Analysis Software on Digital Models Obtained by 3D Scans of Plaster Casts: Intrarater Reliability and Validity. Journal of Orofacial Orthopedics, 77, 22-30. https://doi.org/10.1007/s00056-015-0004-2

[19] Dubula, V.G. (2016) Comparison of the Accuracy of Digital Models Obtained from Scans of Impressions versus Direct Intra-Oral Scans. Master Thesis, University of the Western Cape, Cape Town, South Africa.

[20] Jiménez-Gayosso, S.I., Lara-Carrillo, E., López-González, S., Medina-Solís, C.E., Scougall-Vilchis, R.J., Hernández-Martínez, C.T., Colomé-Ruiz, G.E. and Escoffié-Ramirez, M. (2018) Difference between Manual and Digital Measurements of Dental Arches of Orthodontic Patients. Medicine, 97, e10887. https://doi.org/10.1097/MD.0000000000010887

[21] Mangano, A., Beretta, M., Luongo, G., Mangano, C. and Mangano, F. (2018) Conventional Vs Digital Impressions: Acceptability, Treatment Comfort and Stress among Young Orthodontic Patients. The Open Dentistry Journal, 12,118-124. https://doi.org/10.2174/1874210601812010118

[22] Medina-Sotomayor, P., Pascual-Moscardo, A. and Camps, A.I. (2018) Accuracy of 4 Digital Scanning Systems on Prepared Teeth Digitally Isolated from a Complete Dental Arch. The Journal of Prosthetic Dentistry, 121, 811-820.

[23] Yoon, J.H., Yu, H.S., Choi, Y., Choi, T.H., Choi, S.H. and Cha, J.Y. (2018) Model Analysis of Digital Models in Moderate to Severe Crowding: In Vivo Validation and Clinical Application. BioMed Research International, 2018, Article ID: 8414605. https://doi.org/10.1155/2018/8414605

[24] Abizadeh, N., Moles, D.R. O’Neill, J. and Noar, J.H. (2012) Digital versus Plaster Study Models: How Accurate and Reproducible Are They? Journal of Orthodontics, 39, 151-159. https://doi.org/10.1179/1465312512Z.00000000023

[25] Brown, G.B., Currier, G.F., Kadioglu, O. and Kierlb, J.P. (2018) Accuracy of 3-Dimensional Printed Dental Models Reconstructed from Digital Intraoral Impressions. American Journal of Orthodontics and Dentofacial Orthopedics, 154, 733-739. https://doi.org/10.1016/j.ajodo.2018.06.009

[26] Porter, J.L., Carrico, C.K., Lindauer, S.J. and Tufeki, E. (2018) Comparison of Intraoral and Extraoral Scanners on the Accuracy of Digital Model Articulation. Journal of Orthodontics, 45, 275-282. https://doi.org/10.1080/14653125.2018.1500773

[27] Tomita, Y., Uechi, J., Konno, M., Sasamoto, S., Iijima, M. and Mizoguchi, I. (2018) Accuracy of Digital Models Generated by Conventional Impression/Plaster-Model Methods and Intraoral Scanning. Dental Materials Journal, 37, 628-633. https://doi.org/10.4012/dmj.2017-208

[28] Berman, G. (2010) Tooth Size Measurements and Bolton Analysis for Fast-Set Plaster Models Versus Computer-Based Models Rendered from Dual Four Alginate Impressions. Master Thesis. University of Pittsburgh, Pittsburgh, Pennsylvania.

[29] El-Zanaty, H.M. El-Beialy, A.R. Abou El-Ezz, A.M., Attia, K.H., El-Bialy, A.R. and Mostafa, Y.A. (2010) Three-Dimensional Dental Measurements: An Alternative to Plaster Models. American Journal of Orthodontics and Dentofacial Orthopedics, 137, 259-265. https://doi.org/10.1016/j.ajodo.2008.04.030 
[30] Naidu, D. and Freer, T.J. (2013) Validity, Reliability, and Reproducibility of the iOC Intraoral Scanner: A Comparison of Tooth Widths and Bolton Ratios. American Journal of Orthodontics and Dentofacial Orthopedics, 144, 304-310.

https://doi.org/10.1016/j.ajodo.2013.04.011 